\title{
Design and Implementation of Bi-Directional DC-DC Converter for Wind Energy System
}

\author{
K. Suresh1, Dr. R. Arulmozhiyal² \\ ${ }^{1}$ Anna University, Chennai, India \\ ${ }^{2}$ Department of Electrical and Electronics Engineering, Research Head SONA-PEDAC, Sona College of Technology, Salem, India \\ Email: sureshk340@gmail.com, aarulmozhiyal@gmail.com
}

How to cite this paper: Suresh, K. and Arulmozhiyal, Dr.R. (2016) Design and Implementation of Bi-Directional DC-DC Converter for Wind Energy System. Circuits and Systems, 7, 3705-3722. http://dx.doi.org/10.4236/cs.2016.711311

Received: April 26, 2016

Accepted: May 15, 2016

Published: September 13, 2016

Copyright $\odot 2016$ by authors and Scientific Research Publishing Inc. This work is licensed under the Creative Commons Attribution International License (CC BY 4.0).

http://creativecommons.org/licenses/by/4.0/ (c) (i) Open Access

\begin{abstract}
This paper proposes a design and implementation of the bi-directional DC-DC converter for Wind Energy Conversion System. The proposed project consists of boost DC/DC converter, bi-directional DC/DC converter (BDC), permanent magnet DC generator and batteries. A DC-DC boost converter is interface with proposed wind system to step up the initial generator voltage and maintain constant output voltage. The fluctuation nature of wind makes them unsuitable for standalone operation. To overcome the drawbacks an energy storage device is used in the proposed system to compensate the fluctuations and to maintain a smooth and continuous power flow in all operating modes to load. Bi-directional DC-DC converter (BDC) is capable of transforming energy between two DC buses. It can operate as a boost converter which supplies energy to the load when the wind generator output power is greater than the required load power. It also operates in buck mode which charges from DC bus when output power is less than the required load power. The proposed converter reduces the component losses and increases the performance of the overall system. The complete system is implemented in MATLAB/SIMULINK and verified with hardware.
\end{abstract}

\section{Keywords}

Bidirectional DC/DC Converter, Boost DC/DC Converter, Wind Turbine Generation System (WTGS), Permanent Magnet DC Generator (PMDC)

\section{Introduction}

The growth in the global energy consumption is predicted to be $1.6 \%-1.7 \%$ per year. The global consumption is going to hit $28 \mathrm{TW}$ by the year 2050. As the demand for energy is rising day by day, most of the global power demand is supplied by burning 
fossil fuels which causes global warming and pollution. Coal power plants contribute $59 \%$ of total sulphur dioxide pollution and $18 \%$ total nitrous oxide per year. Only $15 \%$ of the coal is converted as electrical energy. For producing 1 unit of power, total carbon emitted is $0.8 \mathrm{Kg}$. Renewable energy is now emerging energy production system which produces eco-friendly, pollution free energy from the natural sources like sunlight, wind, geothermal, tidal etc. Renewable energy will contribute the global effort to meet the challenges of climatic changes by providing clean energy [1].

Renewable energy sources including wind power offer a feasible solution to distributed power generation for isolated communities where utility grids are not available. In such cases, stand-alone wind energy systems (i.e., systems not connected to the utility grid) can be considered as an effective way to provide continuous power to electrical loads [2] [3].

The primary objective of this project is to simulate and implement a system, and is to harness wind energy in an efficient way [4]. Among the available harnessing systems of wind energy, the proposed system has been proved to be more efficient. The conventional harnessing system consists of DC-DC converter, and charge controller. There are several stages of conversion [5] [6]. Thus it increases the complexity, size and cost of the system. The proposed system consists of bi-directional DC-DC converter and control circuits [7] [8]. The power conversion unit features a wind-turbine-driven PMSG [9], a diode rectifier, a bidirectional buck-boost DC/DC converter, a battery bank, and a DC/AC inverter [10]-[12]. The proposed converter reduces the component losses and increases the performance of the overall system. The complete system is shown as block diagram in Figure 1 and implemented in MATLAB/SIMULK. Proposed work takes input source as wind from wind turbine and delivers constant power using bidirectional converter and SPEEDGOAT controller to drive motor load and lamp loads.

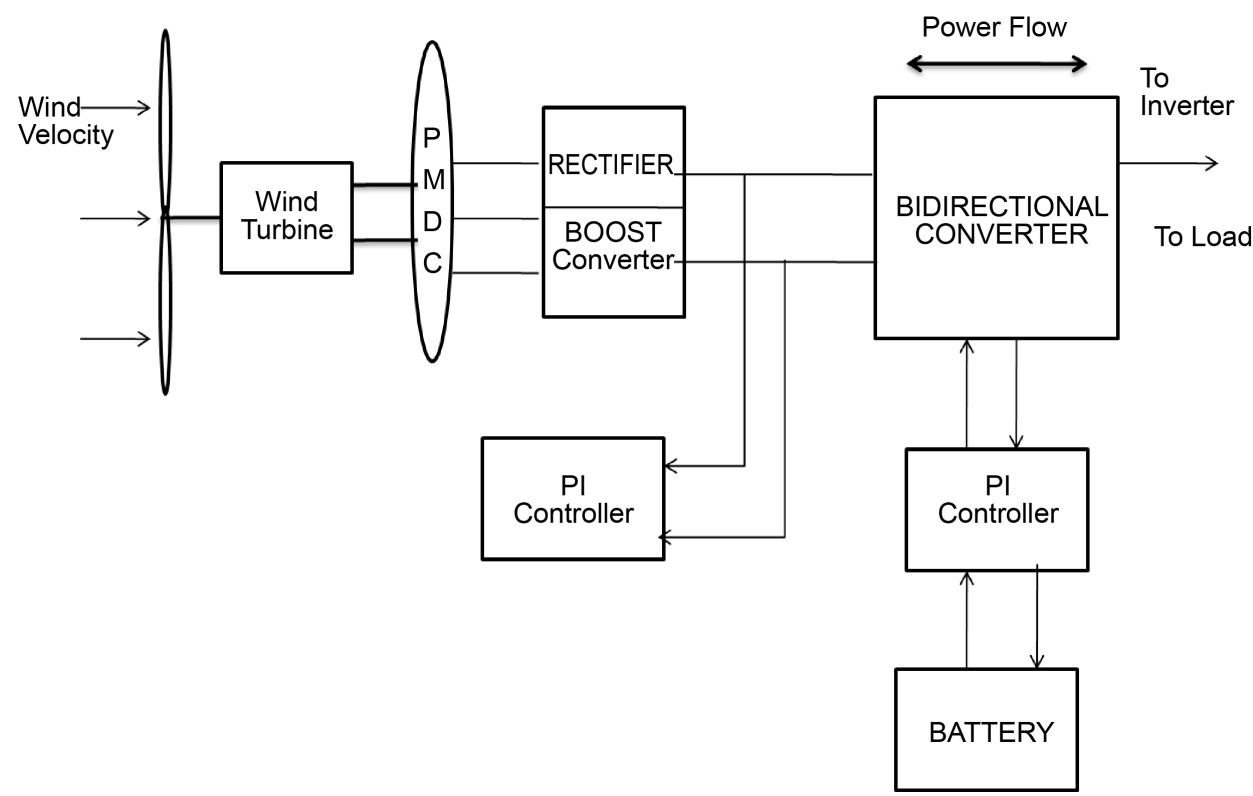

Figure 1. Overall system of proposed drive. 


\section{System Configuration of Converter}

A DC-DC boost converter is interface with proposed wind system to step up the initial generator voltage and maintain constant output voltage. The fluctuation nature of wind makes them unsuitable for standalone operation. To overcome the drawbacks an energy storage device is used in the proposed system to compensate the fluctuations and to maintain a smooth and continuous power flow in all operating modes to load. Bidirectional DC-DC converter (BDC) is capable of transforming energy between two DC buses. It can operate as a boost converter which supplies energy to the load when the wind generator output power is greater than the required load power. It also operate buck converter which charges the battery from the DC bus when output power is less than the required load power.

\subsection{Wind Turbine}

Wind turbine is a rotating machine which converts the kinetic energy in wind into mechanical energy. If the mechanical energy is then converted to electricity, the machine is called a wind generator, wind turbine, wind power unit (WPU), wind energy converter (WEC), or aero generator. Wind turbines can be separated into two types based by the axis in which the turbine rotates. Turbines that rotate around a horizontal axis are more common. Vertical-axis turbines are less frequently used.

Horizontal-axis wind turbines (HAWT) have the main rotor shaft and electrical generator at the top of a tower, and must be pointed into the wind. Most have a gearbox, which turns the slow rotation of the blades into a quicker rotation that is more suitable to drive an electrical generator.

\subsection{Power Production from Wind Energy}

The mechanical power of the wind passing an area of $A$ with speed $v$ is,

$$
P=0.5 * \rho^{*} A^{*} v^{3}
$$

where, $\rho$ is the density of air. The density of air varies with the air temperature and pressure. For the wind turbine rotor shown in Figure 2 the area swept by the rotor blades is $A$ and the turbine slows the wind from speed $v_{1}$ (wind speed at the entrance of the rotor blades) to $v_{2}$ (wind speed at the exit of the rotor blades). Since $A_{2}>A_{1}$ then $v_{1}>v_{2}$.

It can be noted from the previous equation that the power of the wind varies linearly with the air area swept by rotor blades and with the cube of wind speed.

Assuming constant pressure and hence constant air density, the mass air flow is the same after and before the turbine

$$
\frac{\mathrm{d} m}{\mathrm{~d} t}=\frac{\mathrm{d}}{\mathrm{d} t}(\rho v)=\rho \frac{\mathrm{d} V}{\mathrm{~d} t}=\rho A v=\rho A_{2} v_{2}
$$

where $V$ is the air volume and $v$ is the wind speed at the height of the turbine rotor. Moreover, $v$ is the average of winds speeds $v_{1}$ and $v_{2}$.

That is, 


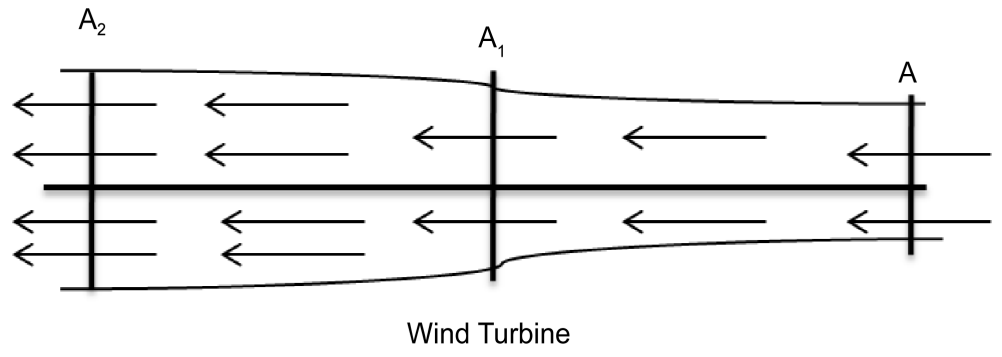

Figure 2. Change of wind speed at a wind turbine.

$$
v=\frac{\left(v_{1}+v_{2}\right)}{2}
$$

And the mechanical power taken from or extracted the wind after passing through the turbine

$$
P_{T}=0.5 * \rho^{*} A^{*}\left(v_{1}+v_{2}\right) *\left(v_{1}^{2}-v_{2}^{2}\right)
$$

The power content of wind passing through the area $A$ in the absence of the turbine is

$$
P=0.5^{*} \rho^{*} A^{*} v^{3}
$$

Hence, the power coefficient $C_{P}$ or rotor coefficient which is the ratio between $P_{T}$ and $P$ is found

$$
C_{P}=\frac{P_{T}}{P}=0.5 *\left(1-\frac{v_{2}^{2}}{v_{1}^{2}}\right) *\left(1+\frac{v_{2}}{v_{1}}\right)
$$

That represents the fraction of the upstream wind power that is extracted by the rotor blades. It can be shown that $C_{P}$ is at its maximum when

$$
\frac{v_{2}}{v_{1}}=\frac{1}{3}
$$

which is the ideal wind speed ratio, the maximum power coefficient will be

$$
C_{P} \approx 0.593
$$

This is often called Betz Power Coefficient and it means that theoretically about $60 \%$ of the wind power is taken by the turbine if it slows the air to one-third of its original speed.

However, practical wind turbines have power coefficient values ranging from 0.4 to 0.5 for modern high-speed turbines and between 0.2 to 0.4 for low speed turbines with more blades. The efficiency of the wind turbine would then be the ratio of the power taken to the ideal usable power

$$
\eta=\frac{P_{T}}{C_{p, \max } \cdot P}=\frac{C_{P} \cdot P}{C_{p, \max } \cdot P}=\frac{C_{P}}{C_{p, \max }}
$$

In summary, the maximum power output of the turbine per square meter of rotor swept area is (assume rotor coefficient equal to $1 / 2$ ) 


$$
P_{T, \max }=\frac{0.5 * 0.5 * A^{*} \rho^{*} v^{3}}{A}=0.25 * \rho^{*} v^{3}
$$

The power extracted by the wind turbine increases with raise of $C_{P}$. However $C_{P}$ is limited by the aeromechanics. $C_{P}$ is also affected by the variation of generator tip speed ratio (TSR) as follows:

$$
\lambda=\frac{\omega R}{V}
$$

where $\omega$ is the wind generator rotor speed of rotation $(\mathrm{rad} / \mathrm{sec}), \mathrm{R}$ is the radius of the area shift by the wind turbine blades.

\subsection{Operating Principle of Boost Converter}

Figure 3 shows a simplified schematic of the boost power stage. Inductor L and capacitor $\mathrm{C}$ make up the effective output filter. The capacitor equivalent series resistance (ESR), RC, and the inductor DC resistance, RL, are included in the analysis. Resistor R represents the load seen by the power supply output.

A power stage can operate in continuous or discontinuous inductor current mode. In continuous inductor current mode, current flows continuously in the inductor during the entire switching cycle in steady-state operation. In discontinuous inductor current mode, inductor current is zero for a portion of the switching cycle. It starts at zero, reaches peak value, and return to zero during each switching cycle. It is desirable for a power stage to stay in only one mode over its expected operating conditions because the power stage frequency response changes significantly between the two modes of operation.

Neglecting the voltage drops across the diode and the transistor:

$$
\begin{gathered}
V_{O}=\frac{V_{i}}{(1-D)} \\
D=\frac{T_{\text {on }}}{T_{\text {on }}+T_{\text {off }}}=\frac{T_{\text {on }}}{T_{s}} \\
T_{s}=\frac{1}{f_{s}}
\end{gathered}
$$

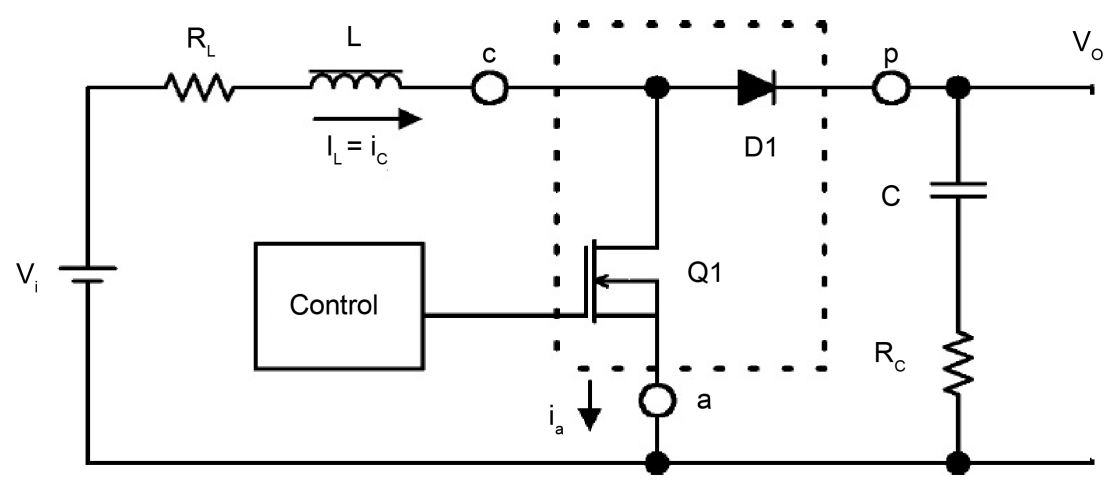

Figure 3. Boost power stage schematic circuit. 
where, $V_{i}$ and $V_{o}$ is the Output Voltage and input voltage of boost converter, $D$ is Duty Cycle, $T_{\text {on }}$ is turn on time, $T_{\text {off }}$ is turn off time, $T_{s}$ is switching time, $f_{s}$ is switching frequency.

\subsection{Inductor and Capacitor Selection of Boost Converter}

The inductor acts as the magnetic field storage element. It stores energy in its core material. The PWM functions as the switch control and the transistor acts as the switch element. The diode and the capacitor are used to perform the function of the output rectifier and filter block.

The value of the boost converter inductor is

$$
L=\frac{D V_{i} T_{s}}{\Delta I_{O \max }}
$$

The value of the boost converter capacitor is

$$
C=\frac{D I_{O \max } T_{s}}{\Delta V_{O}}
$$

where, Ripple in maximum output current $\Delta I_{O \max }=10 \%$ of $I_{O \max }$, Ripple output voltage $\Delta V_{o}=(0.02 \%$ to $0.05 \%)$ of $V_{o}$.

\section{Modeling of Bidirectional Buck-Boost Converter}

Bidirectional DC-DC converters (BDC) have recently received a lot of attention due to the increasing need to systems with the capability of bidirectional energy transfer between two DC buses. Basic DC-DC converters such as buck and boost converters (and their derivatives) do not have bidirectional power flow capability. This limitation is due to the presence of diodes in their structure which prevents reverse current flow. In general, a unidirectional DC-DC converter can be turned into a bidirectional converter by replacing the diodes with a controllable switch in its structure.

Figure 4 shows the structure of elementary buck and boost converters and how they can be transformed into bidirectional converters by replacing the diodes in their structure. It is noteworthy that the resulted converter has the same structure in both cases.

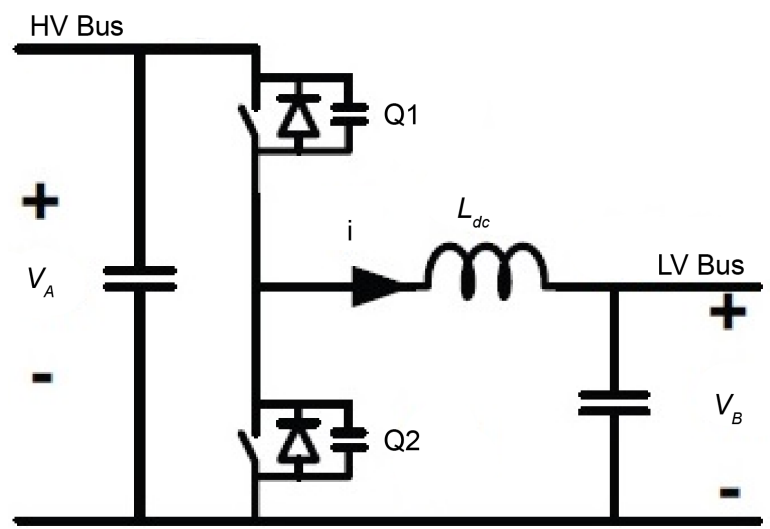

Figure 4. Bi-directional buck boost converter circuit. 
Mode 1 (Boost Mode): In this mode switch Q2 and diode D1 enters into conduction depending on the duty cycle whereas the switch Q1 and diode D2 are off all the time. This mode can further be divided into two interval depending on the conduction on the switch Q1 and diode D2 as shown in the Figure 5.

Interval 1 (Q2-on, D2-off; Q1-off, D2-off): In this mode Q2 is on and hence can be considered to be short circuited, therefore the lower voltage charges the inductor and the inductor current goes on increasing till not the gate pulse is removed from the Q2. Also since the diode D1 is reversed biased in this mode and the switch Q1 is off, no current flows through the switch Q1.

Interval 2 (Q1-off, D1-off; Q2-off, D2-on): In this mode Q2 and Q1 both are off and hence can be considered to be opened circuited. Now, since the current owing through the inductor cannot change instantaneously, the polarity of the voltage across it reverses and hence it starts acting in series with the input voltage. Therefore the diode D1 is forward biased and hence the inductor current charges the output capacitor C2 to a higher voltage. Therefore the output voltage boosts up.

Neglecting the voltage drops across the diode and the transistor:

$$
\text { Voltage across HV BUS, } V_{H}=\frac{V_{L}}{(1-D)}
$$

Mode 2 (Buck Mode): In this mode switch Q1 and diode D2 enters into conduction depending on the duty cycle whereas the switch Q2 and diode D1 are off all the time. This mode can further be divided into two interval depending on the conduction on the switch Q2 and diode D1 as shown in the Figure 6.

Interval 1 (Q2-on, D2-off; Q1-off, D2-Off): In this mode Q1 is on and Q2 is off and hence the equivalent circuit. The higher voltage battery will charge the inductor and the output capacitor will get charged by it.

Interval 2 (Q1-off, D1-off; Q2-off, D2-on): In this mode Q2 and Q1 both are off. Again since the inductor current cannot change instantaneously, it gets discharged

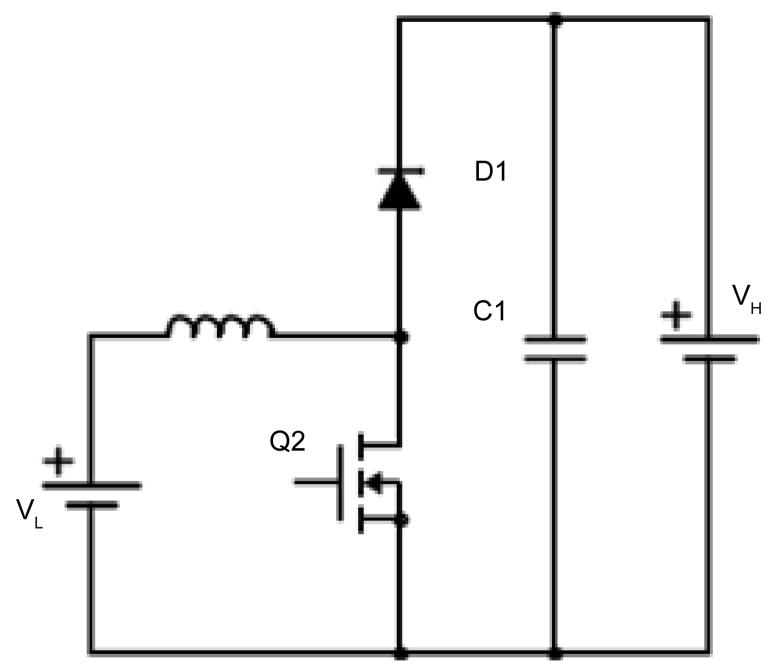

Figure 5. Boost mode operation. 
through the freewheeling diode D2. The voltage across the load is stepped down as compared to the input voltage.

Neglecting the voltage drops across the diode and the transistor:

$$
\text { Voltage across LV BUS, } V_{L}=V_{H} D
$$

\subsection{Inductor and Capacitor Selection}

A major design aspect in a high power converter is the selection of the inductor. The design of the inductors plays a crucial role in the overall converter operation. The major concern here is the size and weight of such a high power inductor that is perhaps the single heaviest component in the entire converter. A small inductance value is preferred in order to reduce the inductor size and weight. A criterion that is simple but reasonable is to have the full (rated) load current operating under DCM/CCM boundary condition and corresponding waveform as shown in Figure 7. Other load conditions will have smaller inductor current under DCM operation.

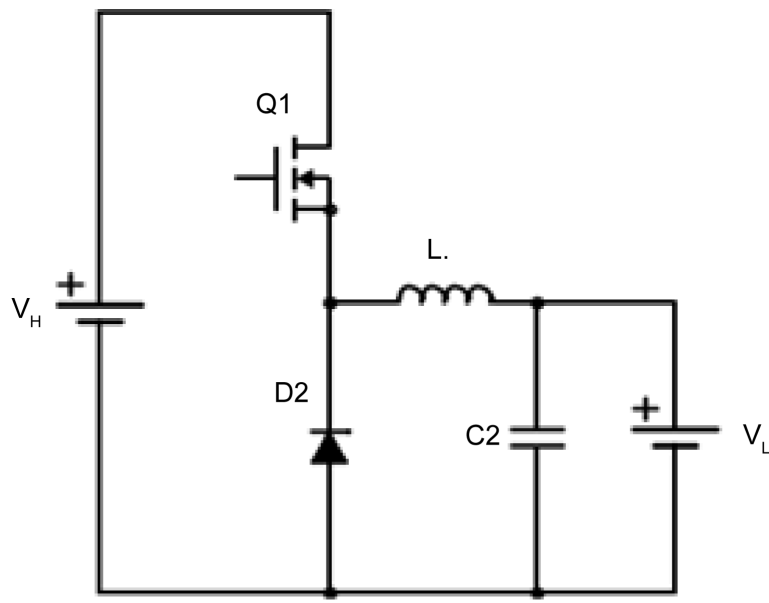

Figure 6. Buck mode operation.

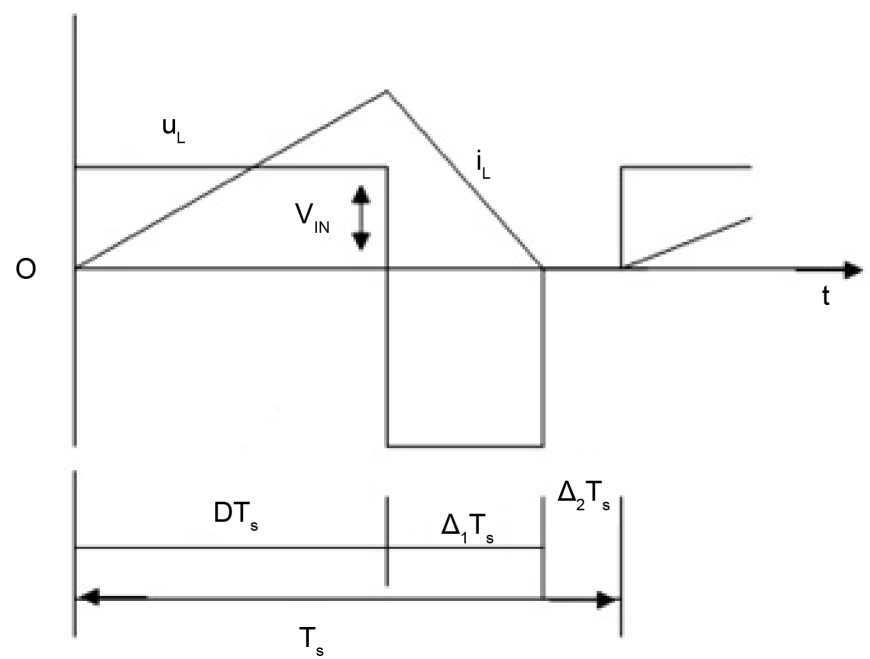

Figure 7. Current waveform during discontinuous conduction mode. 
The equations defining the inductor current during conversion in the DCM mode are as follows:

The minimum inductance value needed to insure the converter operates in CCM is known as the critical inductance value. For the buck and boost converter the critical inductance value is dependent on the steady state duty cycle, switching period and the load resistance. The equation for the critical inductance for the boost converter is given by:

$$
L_{C R, B O O S T}=\frac{T_{S R_{L O A D}}}{2}(1-D)^{2}
$$

Or the above equation can be also written as

$$
L_{C R, B O O S T}=\frac{V_{O}-V_{I N}}{2 P} \frac{V_{I N}^{2}}{V_{O}} T_{s}
$$

Similarly the critical inductance for the buck mode CCM operation is given by

$$
L_{C R, B U C K}=\frac{(1-D) V_{O} T_{s}}{2 I_{O}}
$$

Therefore the value of the converter inductor should be less than the value given by,

$$
L=\min \left[\left(\frac{V_{O}-V_{I N}}{2 P} \frac{V_{I N}^{2}}{V_{O}}\right),\left(\frac{(1-D) V_{O} T_{s}}{2 I_{O}}\right)\right]
$$

Also the output and input capacitor values found from the capacitors voltage ripple are given as below:

$$
\begin{aligned}
& C_{1}=\frac{\Delta I_{L}}{8 \Delta V_{I N}} T_{s} \\
& C_{2}=\frac{V_{O} D}{R_{L O A D} \Delta V_{O}} T_{s}
\end{aligned}
$$

Also the inductor ripple current is given by the equation

$$
\Delta I_{L}=\frac{V_{O}-V_{I N}}{2 L} \frac{V_{I N}}{V_{O}} T_{s}
$$

where, $\Delta V_{O}$ is output ripple voltage, $\Delta I_{L}$ is inductor ripple, current, $T_{s}$ is switching time, $f_{s}$ is witching frequency, $R_{L O A D}$ is load resistance, $P$ is maximum power rating.

\subsection{Controller}

Bi-directional converter operating in continuous conduction mode (CCM) controls the DC voltage by controlling the duty cycle. This controller maintains a constant voltage at output side both boost and buck operation. Duty cycle of both switches produces by above controller. This controller is composed by two nested loops with PI controller. Output voltage and inductor current are feedback signals to PI controller. The main loop of voltage provides reference for the interior current loop as shown in Figure 8. $V_{C}$ is the control signal for two switches. Controller process the feedback of voltage and current loop from load side and battery state of charge (SOC) to tune gain values. 


\section{Simulation Analysis and Results}

Bidirectional DC-DC converter with SPEEDGOAT controller as feedback drive and operating input from voltage and current to drive converter and load. Proposed system is developed in MATLAB/SIMULINK and interfaced with SPEEDGOAT controller. In simulation circuit, wind turbine model is use for the input to the PMSG. Wind velocity is given to turbine model by constant block. Boost converter as well as bi-directional converter are implement as per design.

Wind turbine voltage, rectified DC voltage and Boost voltage is obtained in simulation as shown in Figure 9. PMSG voltage waveform is a sinusoidal. It is generated by wind turbine. Rectifier is used to rectify the generator AC voltage into DC voltage. Booster converter is boost the rectify DC voltage into $24 \mathrm{~V}$ and maintain constant by using PI controller.

Figure 10 is output waveform of bidirectional converter, when it was operated in boost mode. The DC input voltage $24 \mathrm{~V}$ is boost to $44 \mathrm{~V}$ by controller pulses. Two nested loop PI controller is used to maintain the constant voltage at the HV bus of the converter. $100 \mathrm{ohm}$ resistance is connected to converter as a load.

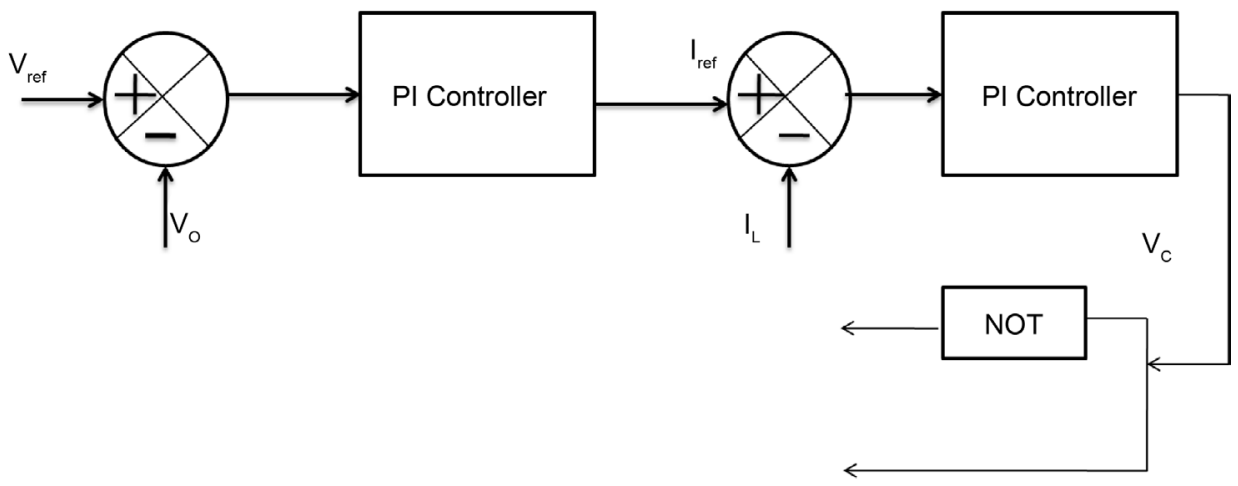

Figure 8. Block diagram of the controller.
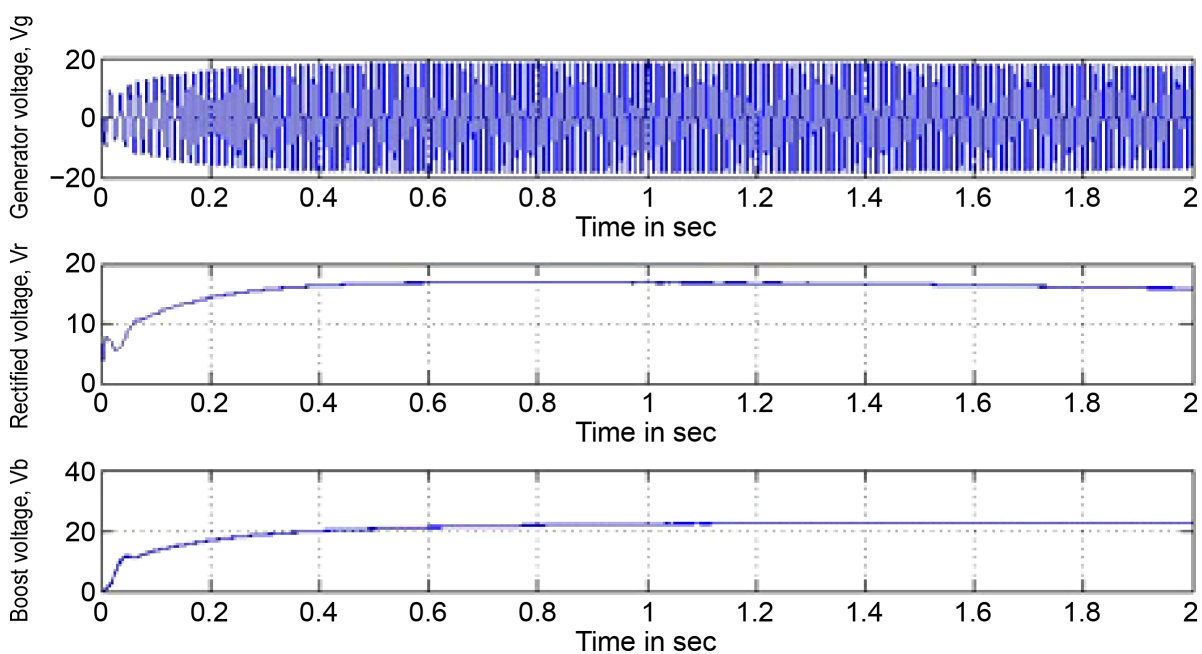

Figure 9. Generator and boost converter output waveform. 
PWM technique used for produce a control pulse to both switches of Bi-directional converter. Figure 11 is gate pulse waveform of the switch Q2.

If the state of charge value is less than or equal to $30 \%$, then the battery operates at charging mode. Boost converter charge the battery by wind power (Figure 12).

If state of charge value is higher than or equal to $80 \%$, then the battery operates at discharge mode. Bi-directional converter boosts the battery voltage and delivers to load. Figure 13 battery state of level reduces and corresponding voltage delivers is charging and discharging using wind power renewable energy power.
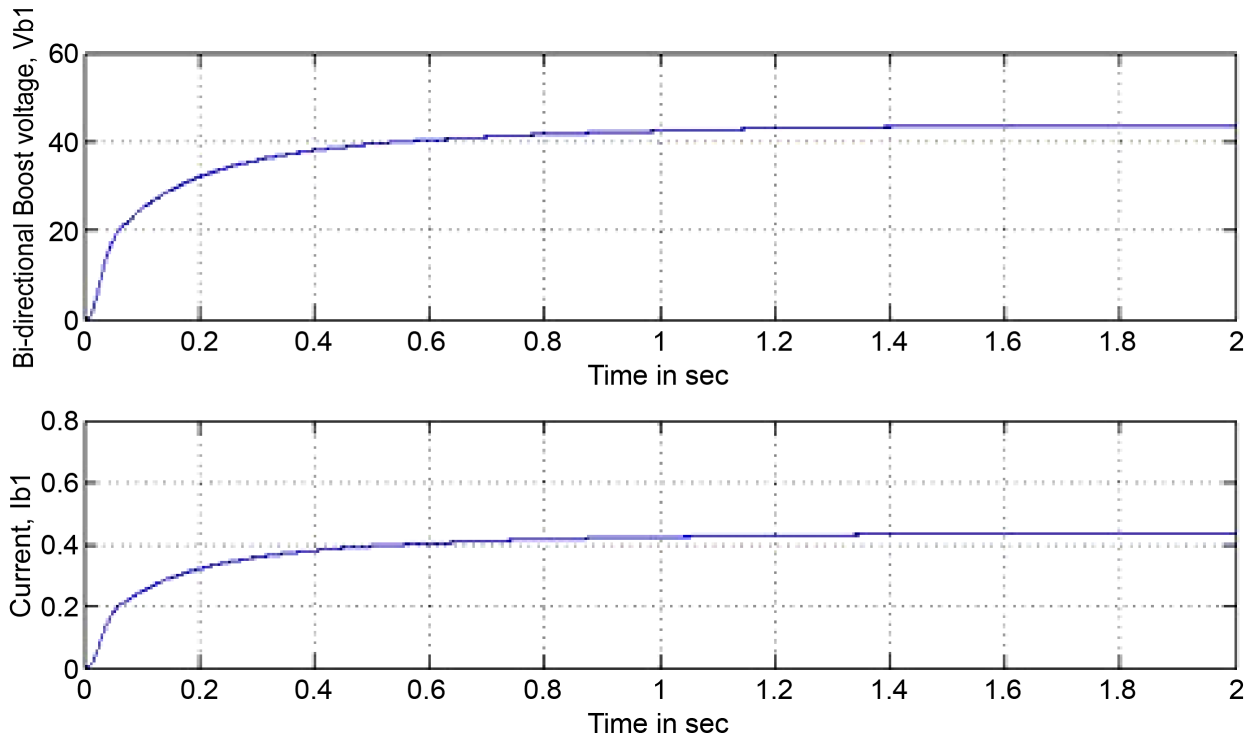

Figure 10. Bi-directional converter output waveforms.
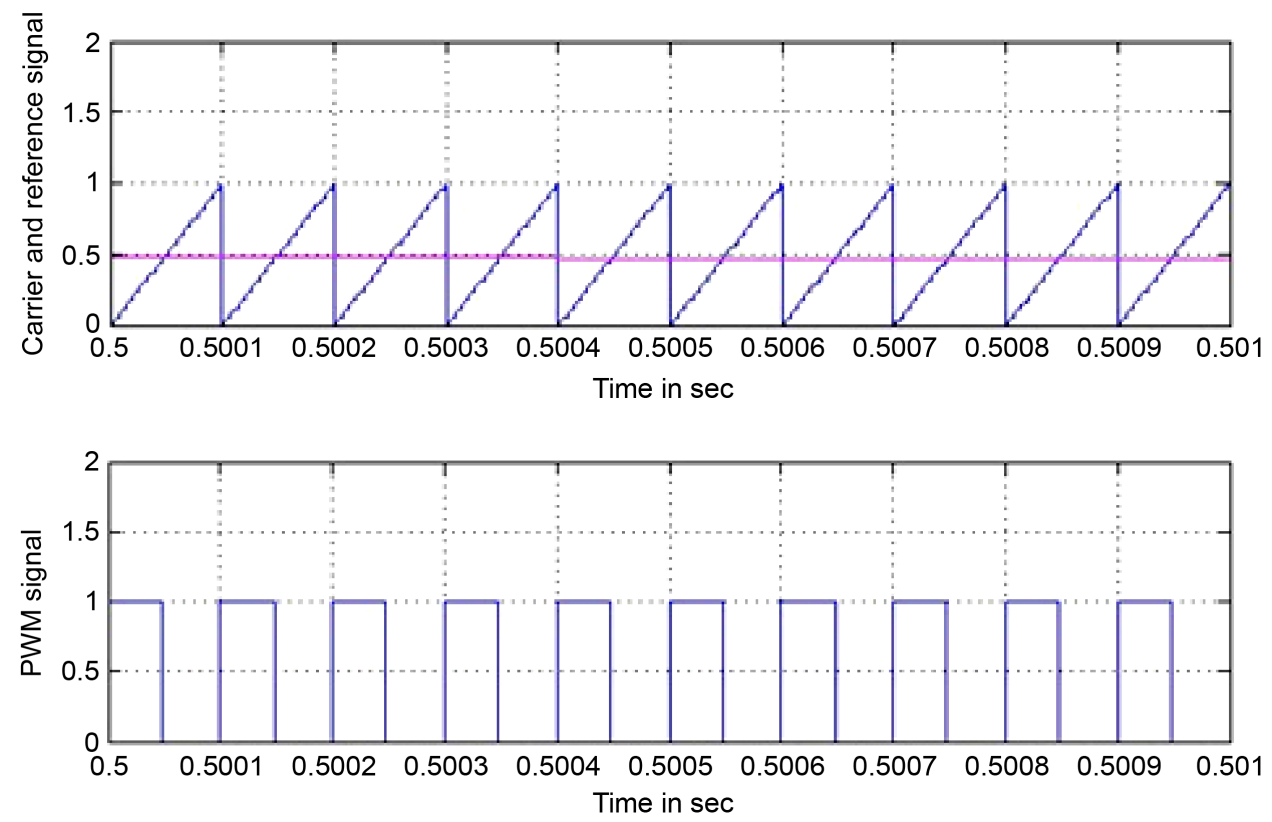

Figure 11. Controller PWM signal. 

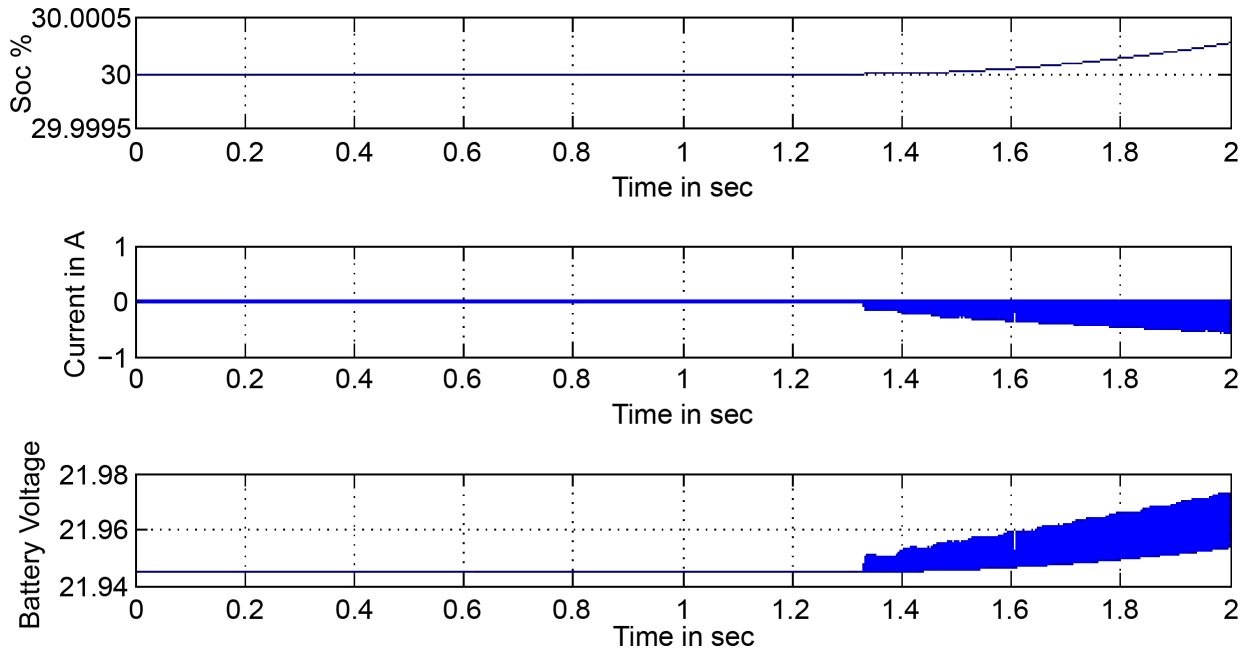

Figure 12. Battery output waveforms during charging.
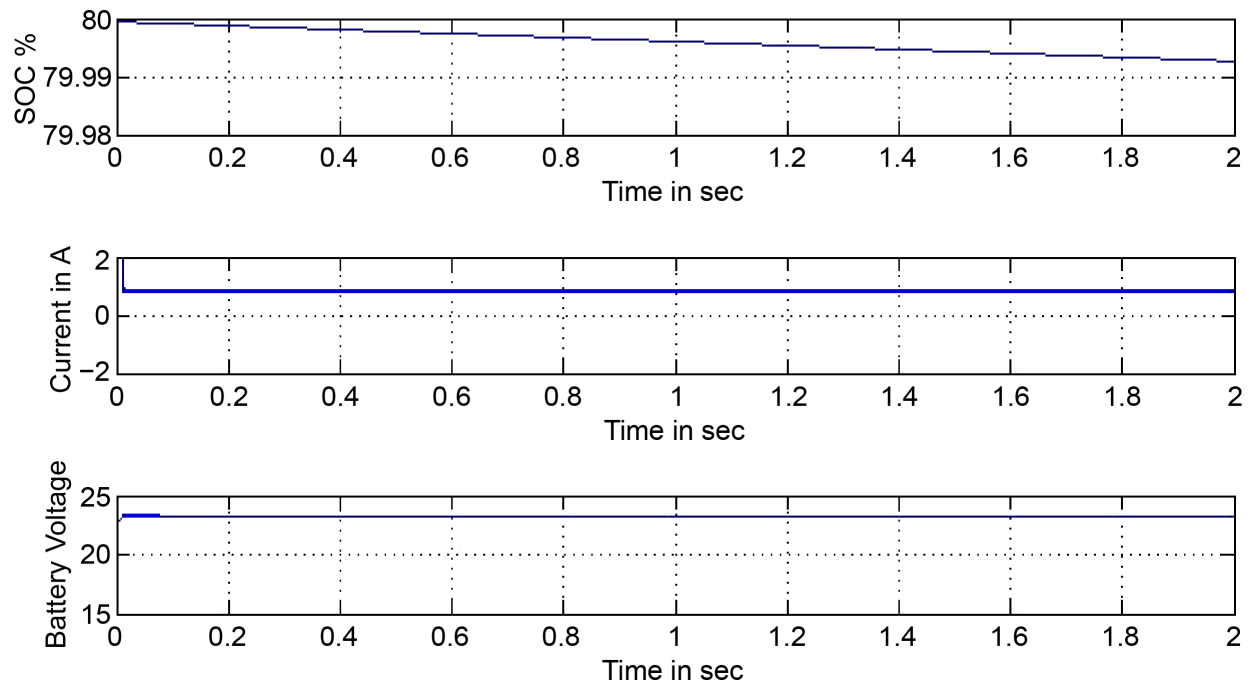

Figure 13. Battery output waveforms during discharging.

The above Figure 14 is output waveform of bidirectional converter when it was operated in buck mode. If the system connected with grid at the same time SOC of the battery below $25 \%$ and wind velocity very low, then Bi-directional converter work as a Buck converter. The DC input voltage $44 \mathrm{~V}$ is buck to $24 \mathrm{~V}$ by controller pulses. Two nested loop PI controller is used to maintain the constant voltage at the LV bus of the converter. In this mode, battery is charge by grid power. So, the current value is negative.

\section{Experimental Setup and Results}

A 100 Watt wind turbine with tail arrangement is arranged with blade length of around 1 meter. 250 watt PMSG is used in this case experimental tests on laboratory prototypes have been carried out to verify the theoretical analysis as shown in Figure 15. Wind 

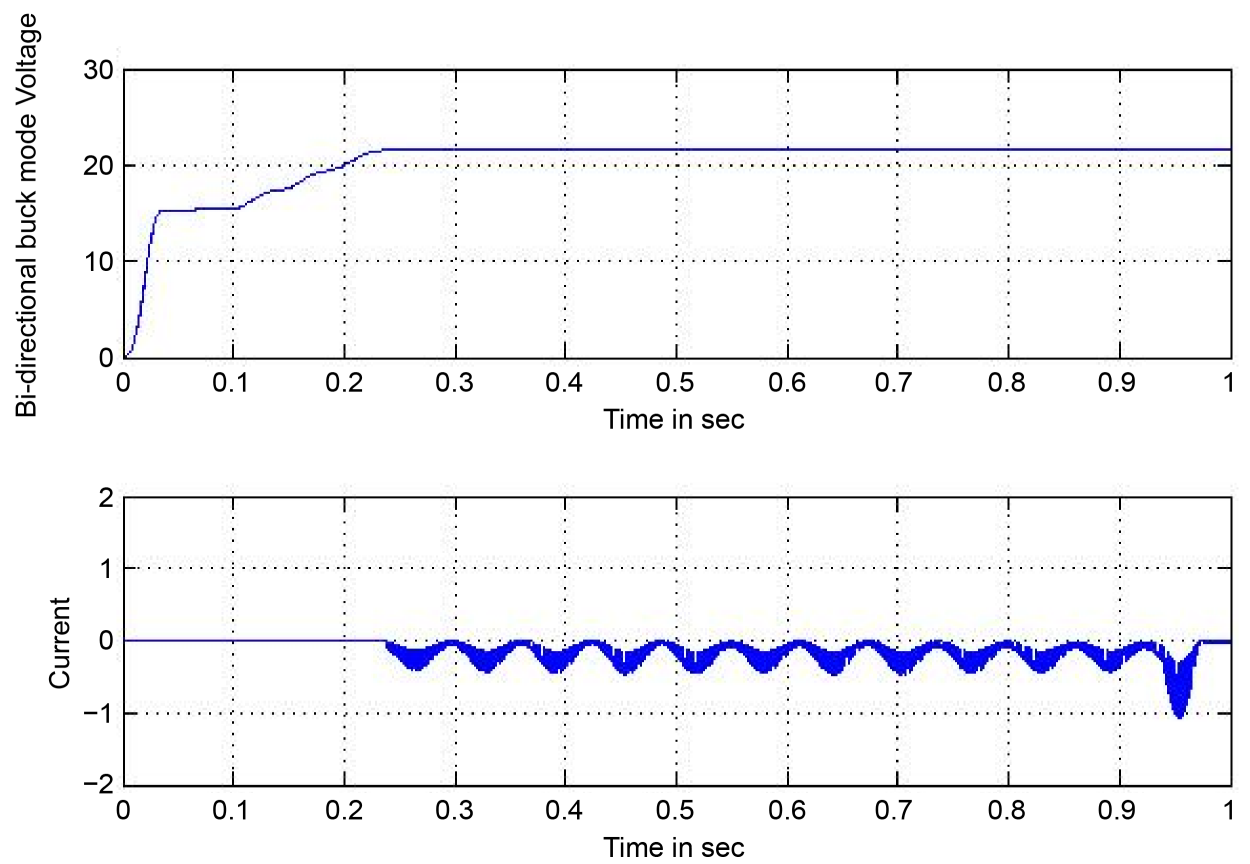

Figure 14. Bi-directional Buck mode converter output waveforms.

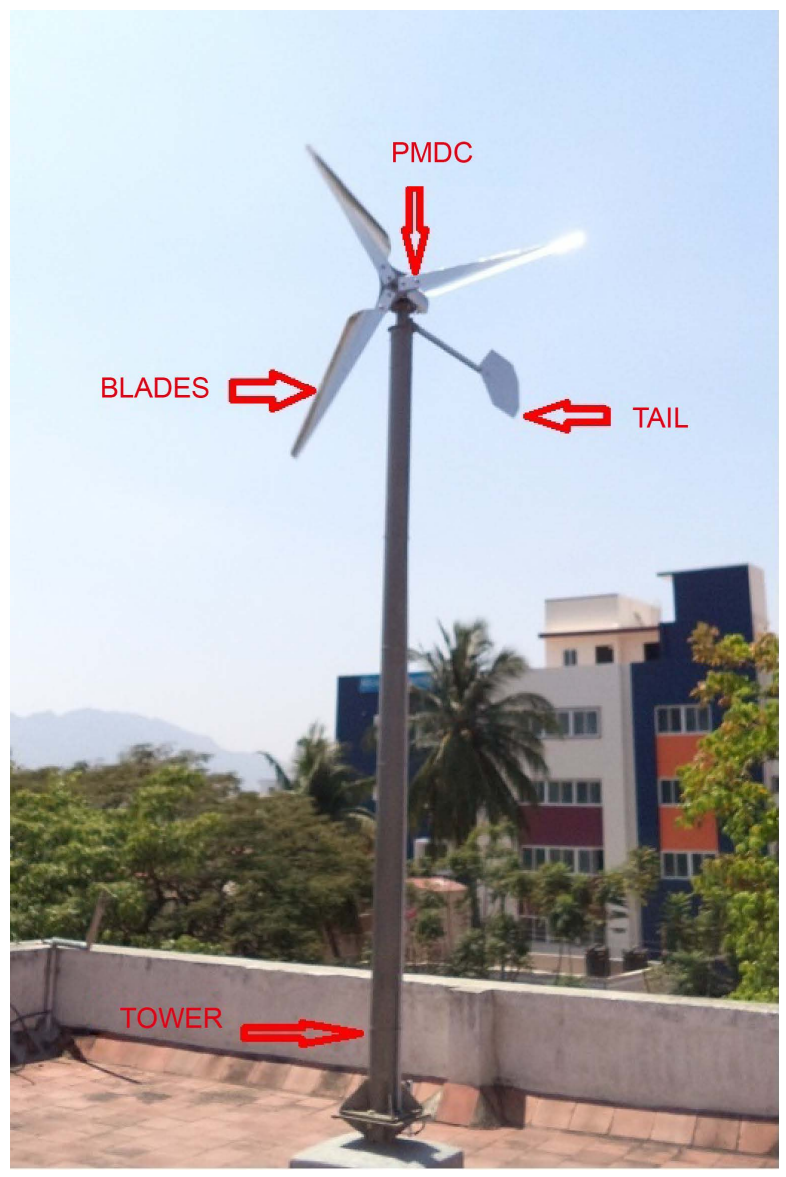

Figure 15. Wind turbine with PMSG. 
power is transferred from wind power through wind generator and rectifier. The experimental platform is shown in Figure 16 and consists of boost converter and bi-directional converter with PMSG. PMSG-based wind turbine produces the electricity from wind power. The wind turbine is rated at 100 watt, which gives a wind power penetration level of around 25\% for the tested system. The boost converter boosts the generator voltage and maintains constant voltage at the output side by PI controller. Output side of the boost converter connected to $24 \mathrm{~V}$ batteries as well as bi-directional LV bus side. 100 watt lamp load is connected to converter as a load at bi-directional HV bus side. Real-time control of the converters was accomplished using a PIC micro controller. Speed goat is a real time target machine, which is used for producing control signal to relay charging circuit. Charging circuit decides whether has to be battery charged or discharged according to the load condition. Speed goat also used to display the converters output waveforms in monitor screen.

The above experimental output waveform is bidirectional converter output voltage and current waveform when it was operated in boost mode. The DC input voltage $24 \mathrm{~V}$ is boosted to $44 \mathrm{~V}$ by controller pulse of SPEEDGOAT as shown in Figure 17. Capacitor filter supplies constant voltage and spikes of filter capacitor is as shown in Figure 18. Experimental output waveform is boost converter output voltage waveform. Boost converters is boosting the generator DC voltage into $24 \mathrm{~V}$ and maintain constant by using PI controller is illustrated from output results.

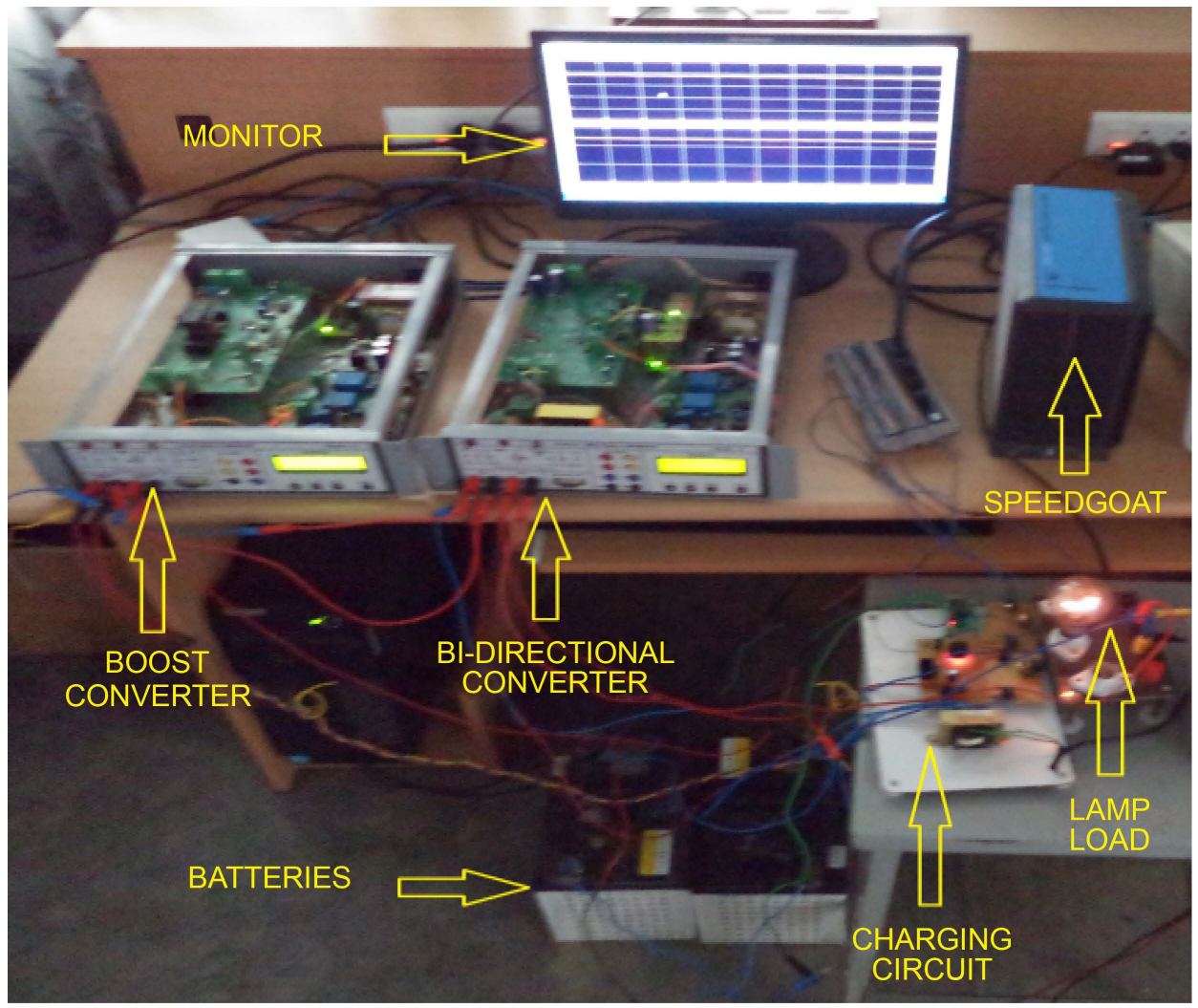

Figure 16. Experimental setup of proposed bi-directional converter. 

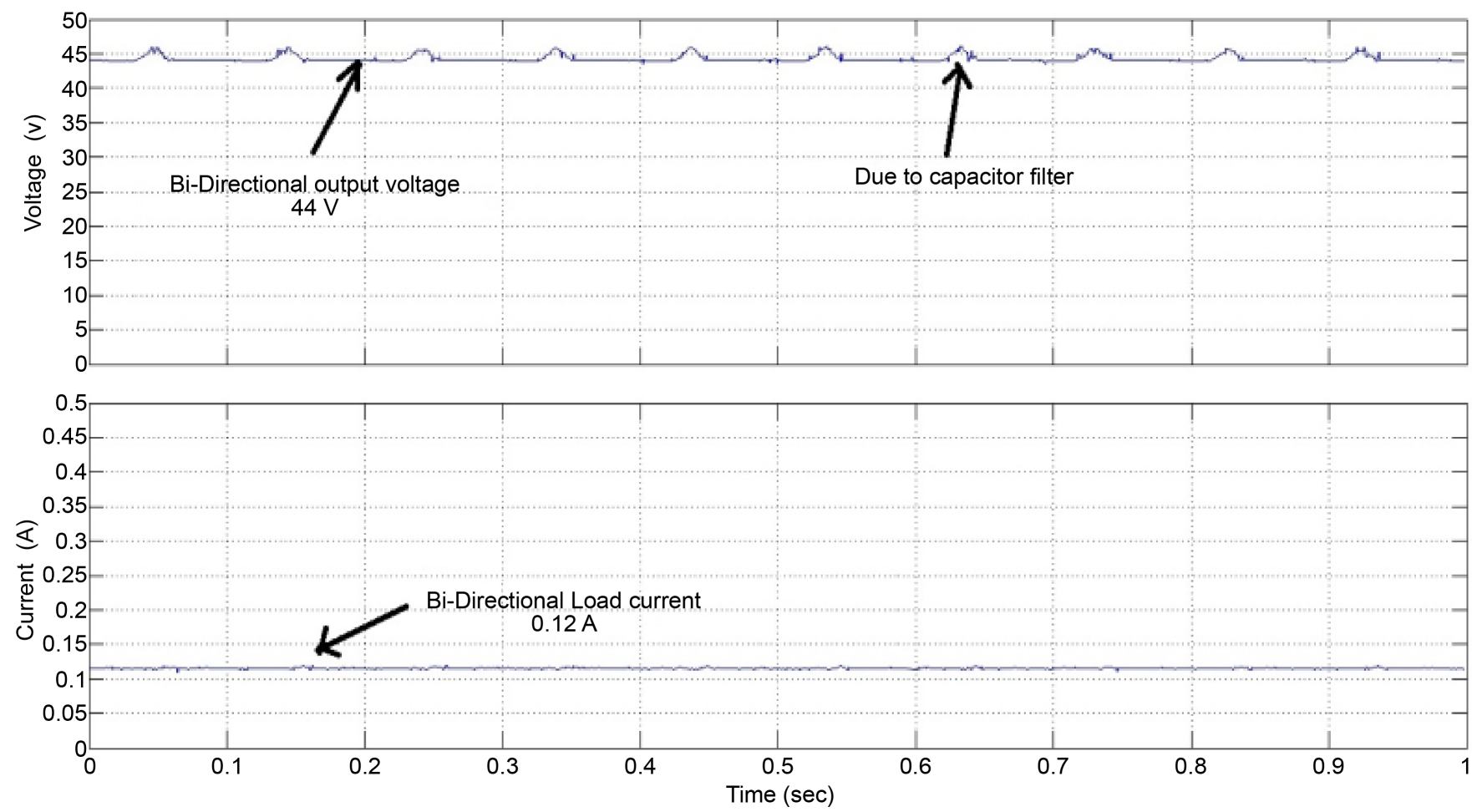

Figure 17. Bi-directional converter output voltage \& current waveforms.

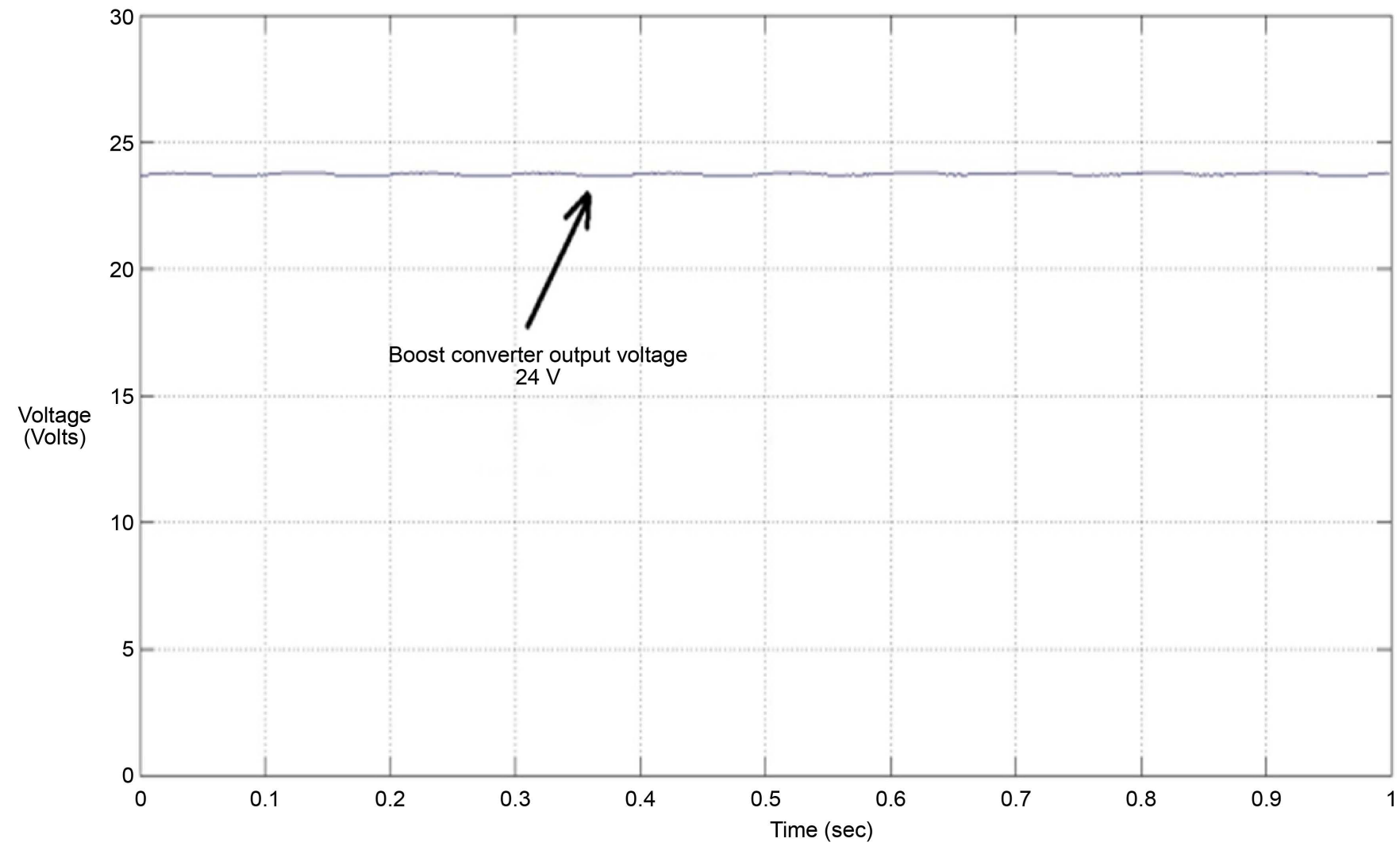

Figure 18. Boost converter output voltage waveform. 
If the state of charge value is less than or equal to $30 \%$, then the battery operates at charging mode. Boost converter charge the battery by wind power. Charging current is $0.35 \mathrm{~A}$. If state of charge value is higher than or equal to $80 \%$, then the battery operates at discharge mode. Bi-directional converter boosts the battery voltage and delivers to load. Discharging current is $0.15 \mathrm{~A}$ as explained in output waveform of Figure 19. Output voltage and current values of experimentally verified using proposed system as represented in Table 1.

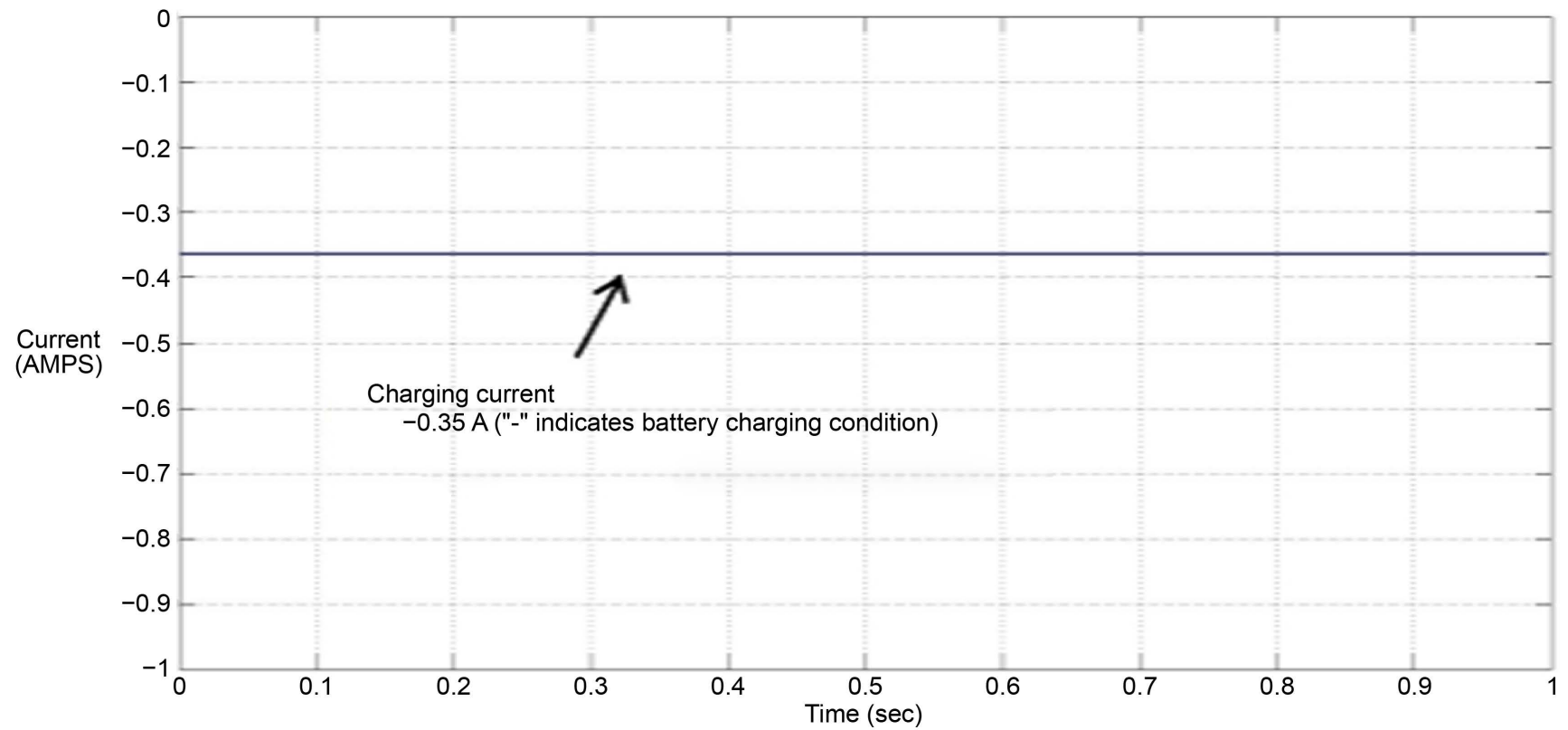

(a)

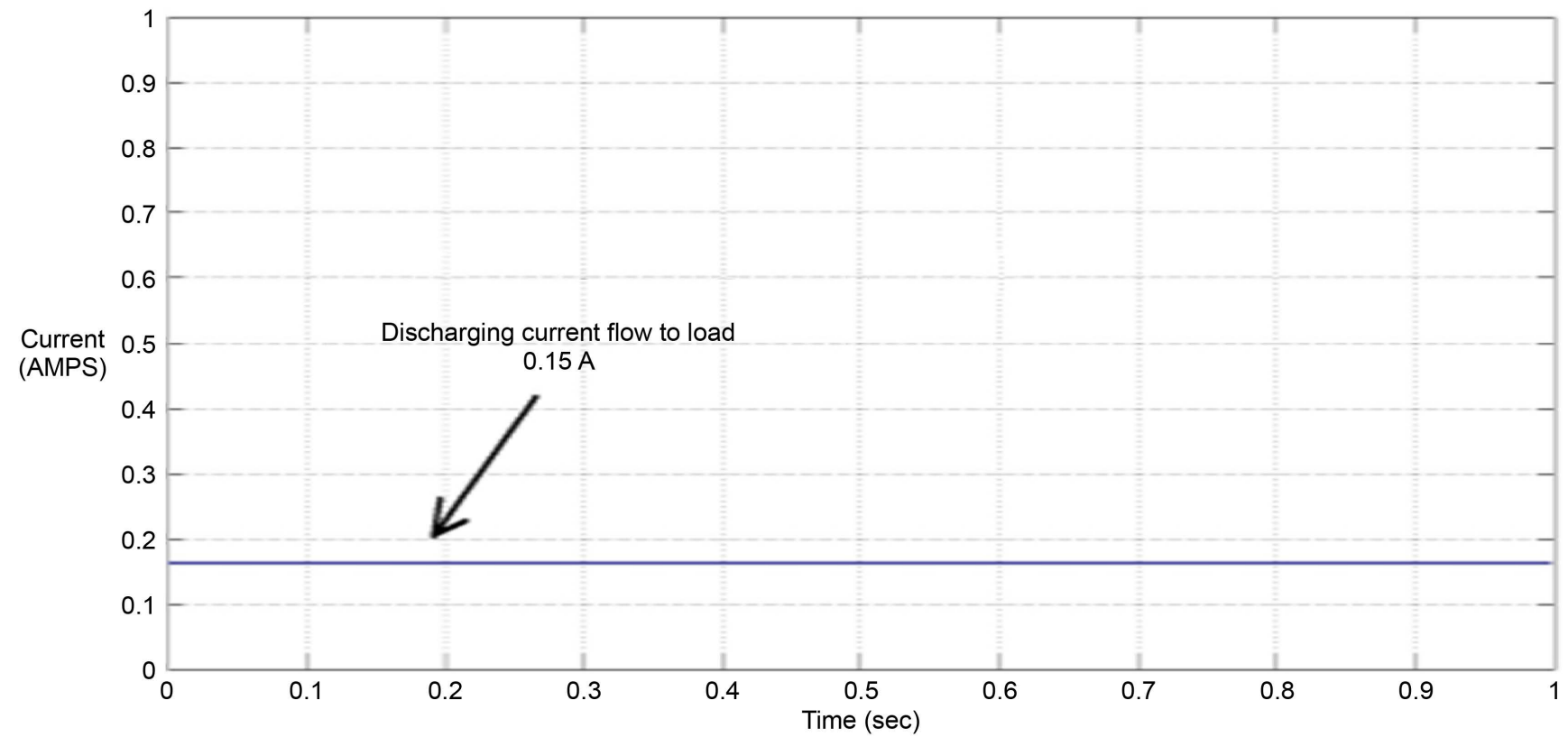

(b)

Figure 19. (a) Charging and (b) Discharging current of batteries. 
Table 1. Output voltage and current values.

\begin{tabular}{clc}
\hline S1. NO. & \multicolumn{1}{c}{ COMPONENTS } & VALUES \\
\hline 1. & Source DC voltage & $12 \mathrm{~V}$ \\
2. & Boost converter output Voltage & $24 \mathrm{~V}$ \\
3. & Bi-directional converter boost mode voltage & $44 \mathrm{~V}$ \\
4. & Battery charging mode current & $0.35 \mathrm{~A}$ \\
5. & Battery discharging mode current & $0.15 \mathrm{~A}$ \\
6. & Lamp load & $100 \mathrm{~W}$ \\
7. & Bi-directional converter boost mode load current & $0.12 \mathrm{~A}$ \\
\hline
\end{tabular}

\section{Conclusion}

In this project, modeling of bi-directional DC-DC converter is developed for wind energy generation and simulated in MATLAB/SIMULINK. The performance of the bi-directional converter using triangle PWM technique has been analyzed from the prospective of input/output characteristics and harmonic content of output voltage and current. The multi-stage current charging method is used to charge the batteries. At various wind speeds, the system can use the battery for energy storage to keep the load voltage and load current stable. Control strategy and system design can be easily implemented and able to improve the efficiency of wind turbine systems.

\section{References}

[1] Kusiak, A., Zhang, Z. and Li, M.Y. (2010) Optimization of Wind Turbine Performance with Data-Driven Models. IEEE Transactions on Sustainable Energy, 1, 66-76. http://dx.doi.org/10.1109/TSTE.2010.2046919

[2] Tita, I. and Calarasu, D. (2009) Wind Power Systems with Hydrostatic Transmission for Clean Energy. Environmental Engineering and Management Journal, 8, 327-334.

[3] Quaschning, V. (2005) Understanding Renewable Energy Systems. Earthscan, London.

[4] Kazimierczuk, M.K. and Czarkowski, D. (1993) Application of the Principle of Energy Conservation to Modeling the PWM Converters. Second IEEE Conference on Control Applications, 13-16 September 1993, 291-296. http://dx.doi.org/10.1109/cca.1993.348274

[5] Miao, Z. and Fan, L. (2012) Modeling and Small Signal Analysis of a PMSG Based Wind Generator with Sensor Less Maximum Power Extraction. 2012 IEEE Power and Energy Society General Meeting, 22-26 July 2012, 1-8.

[6] Bryant, B. and Kazimierczuk, M.K. (2004) Small-Signal Duty Cycle to Inductor Current Transfer Function for Boost PWM DC-DC Converter in Continuous Conduction Mode. Proceedings of the 2004 International Symposium on Circuits and Systems, Vancouver, 23-26 May 2004, 856-859. http://dx.doi.org/10.1109/iscas.2004.1329943

[7] Xu, D.H., Zhao, C.H. and Fan, H.F. (2004) A PWM plus Phase-Shift Control Bidirectional DC-DC Converter. IEEE Transactions on Power Electronics, 19, 666-675.

http://dx.doi.org/10.1109/TPEL.2004.826485

[8] Jain, M., Daniele, M. and Jain, P.K. (2000) A Bidirectional DC-DC Converter Topology for Lowpower Application. IEEE Transactions on Power Electronics, 15, 595-606.

http://dx.doi.org/10.1109/63.849029 
[9] Zhao, Q. and Lee, F.C. (2010) High-Efficiency, High Step-Up DC-DC Converters. IEEE Transactions on Power Electronics, 18, 65-73. http://dx.doi.org/10.1109/TPEL.2002.807188

[10] Patel, M.K. (2006) Wind and Solar Power Systems: Design, Analysis, and Operation. CRC Press, FL.

[11] Blaabjerg, F., et al. (2006) Power Electronics in Renewable Energy Systems. Power Electronics and Motion Control Conference (EPE-PEMC), Portoroz, 30 August-1 September 2006, 1-17. http://dx.doi.org/10.1109/epepemc.2006.4778368

[12] De Broé, A.M., Drouilhet, S. and Gevorgian, V. (1999) A Peak Power Tracker for Small Wind Turbines in Battery Charging Applications. IEEE Transactions on Energy Conversion, 14, 1630-1635. http://dx.doi.org/10.1109/60.815116

\section{Submit or recommend next manuscript to SCIRP and we will provide best service for you:}

Accepting pre-submission inquiries through Email, Facebook, LinkedIn, Twitter, etc. A wide selection of journals (inclusive of 9 subjects, more than 200 journals)

Providing 24-hour high-quality service

User-friendly online submission system

Fair and swift peer-review system

Efficient typesetting and proofreading procedure

Display of the result of downloads and visits, as well as the number of cited articles

Maximum dissemination of your research work

Submit your manuscript at: http://papersubmission.scirp.org/ 